\title{
Attitudes Towards Linkage Mechanism Researh of Agricultural Research and Extension
}

\author{
Ahmad Al-Rimawi, Mohammad Tabieh and Hussein Al-Qudah \\ Department of Agricultural Economics and Agribusiness Management, \\ Faculty of Agriculture, University of Jordan, Amman, 11942, Jordan
}

Received 2012-10-09, Revised 2012-12-31; Accepted 2013-04-18

\begin{abstract}
The aim of this study is to examine how linkages between the actors in the research and extension system in Jordan can be improved to enhance their effectiveness. Likert scales were used as tools for data collection to measure attitudes towards management, organizational and universities linkages using a convenient sample of 121 extension agents and researchers. Cronbach's alpha coefficients were above 0.80 for the three scales, which indicates good reliability. Parametric and non-parametric tests were used to analyze the data, based on approximations of the scales to the normal distribution. Overall attitudes towards linkages were found to be generally high. Researchers' attitudes were significantly higher for some of the managerial interventions, many of the organizational linkages and towards the applicability of the university research. Researchers appear to be relatively younger and more educated, but less experienced. More experienced and trained were more likely to value highly stronger linkages. No significant associations were observed between attitudes and most of the personal characteristics. Positive attitudes to measures that formally integrate research providers and extension contribute to establishing a unified system, with more focused and applied research programs that effectively address high priority local needs.
\end{abstract}

Keywords: Research-Extension Linkages, Attitudes, Management and Organizational Mechanisms

\section{INRODUCTION}

Knowledge and information management and access to technology have become an essential element towards sustainable agricultural development. This was manifested in the World Bank investment of more than five billion dollars in agricultural Research and Extension (R\&E) during the 1980s and 1990s (Rivera et al., 2006). Thus, linkages among various technology transfer agencies in an Agricultural Research and Extension System (ARES) are crucial to enhance the impact of new technologies on farmers. Interdependence and linkages between major institutional actors in an ARES are widely recognized as essential for an effective flow of technology and information between R\&E and farmers (Peterson et al., 2001). Yet, lack of institutional coordination and cooperation has long been noted in developing countries (Swanson, 1997; Marsh and Pannell,
2000) and in the developed countries such as Australia (Murray, 1999). Weak linkages present systematic bottleneck in national agricultural technology systems and can limit their effectiveness in contributing to development (Crowder and Anderson, 1996). Poor linkages between $R \& E$ and policy makers are the norm in the West Asia and North Africa (WANA) region (Belaid et al., 2003; Chizari and Movahedi, 2005).

The ARES in Jordan is basically made up of a semiautonomous institution; the National Center for Agricultural Research and Extension (NCARE) and five Faculties of Agriculture (FAs), with the NCARE accounting for more than two thirds of the total financial resources of the system. In 2007, the agricultural research accounted for $0.3 \%$ of the Agricultural GDP, against $2 \%$ of the AGDP suggested by the World Bank (NCARE, 2009). In general, research facilities of the NCARE such as offices, labs, equipments, information Corresponding Author: Mohammad Tabieh, Department of Agricultural Economics and Agribusiness Management, Faculty of Agriculture, University of Jordan, Amman, 11942, Jordan Tel: ++ 966535500 Fax: ++ 9665300806 
services, farms and land resources are good (Casas, 1999). In contrast, extension has traditionally received less funding and has not been able to recruit people of high competence. In 2008, the Jordanian ARES included 376 scientific academic staff $(70 \%$ with $\mathrm{PhD}$ degrees), of which, NCARE had 141 scientific staff, (38\% are $\mathrm{PhD}$ holders), (NCARE, 2009). But, educational backgrounds differ widely between researchers and extension agents. In addition, NCARE had produced about 100 advisory tri-fold leaflets and some booklets in Arabic on crops, fruit, vegetables, pest and disease control, livestock and fertilizer applications (Qtaishat and AL-Sharafat, 2012). The pressure on the agriculture sector in Jordan is growing due to increasing land fragmentation, continued shortage of water and deterioration of its quality and competition at the international markets. Agricultural research is indispensable for properly addressing such issues (Casas, 1999).

Weaknesses of the R\&E services is well documented and widely acknowledged as one of the major obstacles for agricultural development in Jordan (Taimeh and Sunna, 1999). Research, extension and teaching are the responsibilities of different institutions in Jordan. Although, there are few examples of collaborative efforts involving applied research providers and the universities, staff from universities and applied research programs may be working on similar problems, in isolation from each other. Therefore, there is a substantial gap in working linkages: research activities are undertaken by each institution without consultation with the others working in similar areas, thus resulting in duplication of efforts and waste of time and resources (Rimawi, 2010; Casas, 1999). Redundancies could be reduced and progress enhanced if communications are improved and linkages among teaching, research and extension are well established in a systematic way (Gould and Ham, 2002; Murray, 1999). An effective system emphasizes how agricultural problems are identified, who should or is actually doing what and what are the formal and informal links among the different actors in the system and how the scientific and indigenous knowledge base can be used to develop technological solutions that are suitable for a targeted population, so that it can be recommended by extension and be adopted by farmers who are confronted with these problems (Blum, 1994).

Policy changes, institutional reorganization and the strengthening of organizations are required to enhance R\&E linkages in developing countries (Agbamu, 2000). Linkage mechanisms are used to channel information between groups and to coordinate required tasks in the process of getting relevant technologies to farmers. The operational linkage strategies are organizational and functional linkage strategies (Sadighi, 2005). Two basic types of linkage mechanisms: organizational and managerial (Merrill-Sands, 1992). Organizational mechanisms involve the structural modification of the R\&E organization that are involved in an ARES such as formal merger of $\mathrm{R} \& \mathrm{E}$ at the broader system level, or specific units within research or extension, or the creation of permanent committees. The other major type of linkage mechanisms involves a range of managerial interventions such as collaboration on joint planning and review activities or when researchers and Subject Matter Specialists (SMSs) carry out collaborative program activities, such as on-farm trials and demonstrations (Merrill-Sands, 1992; Swanson, 1997).

Promoting applied research and improving the extension services are given high priority by the Government of Jordan. This was manifested by the adoption of the national plans for research-extension strategies and agricultural policy (NCARTT, 1996; MOA, 1997; 1998; 2001). Yet, reviews of technology transfer activities indicated a substantial gap in R\&E linkages and call for policy changes and institutional reorganization if effective transfer of improved technologies is to be achieved.

\section{MATERIALS AND METHODS}

The purpose of this study is to investigate how linkages between the major institutional actors in the ARES can be improved to enhance the effectiveness of R\&E systems. The specific objectives of the study are the following:

- To examine the researchers and extension agents' attitudes towards management, organizational and universities research-extension linkages

- To investigate the relationships between researchers and extension agents' attitudes and selected professional and demographic characteristics such as education, years of service, number of training courses, sex and age

The study population was the public researchers and extension agents who work for the Ministry of Agriculture (MOA) in Jordan. Primary data was collected by personal interviews using a convenience sample of $68(56 \%)$ researchers and $53(44 \%)$ of 
extension agents. A structured questionnaire was used as a tool for data collection. Three 4-point Likert-type scales were used for data collection to examine the researchers and extension agents' attitudes towards management and organizational R\&E linkages and linkages with universities. The ratings were on a scale of one to four, with one being "strongly disagree", two being "disagree", three being "agree" and four being "strongly agree". The management and organizational R\&E linkages scales consisted of 10 items each and the rates ranged between 10 and 40 points. The linkages with universities scale consisted of 8 items and the rates ranged between 8 and 32 points. Cronbach's alpha coefficients were $0.84,0.85$ and 0.94 for the three scales respectively. Alpha coefficients were above 0.8 for the three scales, which indicates good reliability (Henneman, 2006; Reynaldo and Santos, 1999).

Descriptive and analytical statistics were employed to analyze the data using the SPSS software. Descriptive statistics were used to profile the researchers and the extension agents and to summarize the study scales. The low values of the negative skewness coefficients provide indications of the nearly normal distribution of management and organizational scales. Based on approximations of the three scales to normal distribution using the Kolmogorov-Smirnov (KS) test, the distribution of the management and organization scales appeared to be normal ( $\mathrm{p}>0.10)$. Thus, parametric tests ( $\mathrm{t}$ and ANOVA tests) were used to analyze the data. The distribution of the universities scale appeared not to be normal $(\mathrm{p}<0.05)$ and non-parametric tests (Man Whitney and Kruscal Wallis tests) were used to analyze the data. The test of independence $\left(\chi^{2}\right)$ was used for category data to examine the associations between researchers and extension agents and their levels of attitudes towards ARES linkages.

\section{RESULTS}

The results of this study are summarized in Table 15. Table 1 shows the sample charactrized. Table 2 clarified the attitudes towards research and extension linkages, while Table 3 shows the attitudes towards organizational research and extension linkages. Table 4 explained the attitudes towards universities research linkages and Table 5 shows the associations between attitudes to linkages with selected variables such as sex, age, education, years of services and training courses.

Table 1. Characteristics of researchers and extension agents (121 cases)

\begin{tabular}{|c|c|c|c|c|c|c|}
\hline \multirow[b]{2}{*}{ Characteristic } & \multicolumn{2}{|c|}{ Sample } & \multicolumn{2}{|c|}{ Researchers $(n=68)$} & \multicolumn{2}{|c|}{ Ext. Agents $(n=53)$} \\
\hline & $\mathrm{F}$ & $(\%)$ & $\mathrm{F}$ & $(\%)$ & $\mathrm{F}$ & $(\%)$ \\
\hline Male respondents & 89 & 73.6 & 46 & 67.6 & 43 & 81.1 \\
\hline$<30$ Yrs age category & 27 & 22.7 & 18 & 26.9 & 9 & 17.3 \\
\hline Respondents with an MSc or PhD degree & 35 & 28.9 & 30 & 44.1 & 5 & 9.4 \\
\hline Respondents with $<5$ Yrs experience & 39 & 32.2 & 26 & 38.2 & 13 & 24.5 \\
\hline
\end{tabular}

Table 2. Differences between researchers and extension agents mean scores of the management scale

\begin{tabular}{|c|c|c|c|c|c|c|}
\hline \multirow[b]{2}{*}{ Items } & \multirow[b]{2}{*}{$\begin{array}{l}\text { Overall } \\
\text { Mean }\end{array}$} & \multirow[b]{2}{*}{$\% 95 \mathrm{CI}$} & \multicolumn{2}{|c|}{ Item Mean } & \multirow[b]{2}{*}{ t- Value } & \multirow[b]{2}{*}{$\mathrm{p}$} \\
\hline & & & $\mathrm{R}$ & EA & & \\
\hline Joint assessment of farmers' problems & 3.30 & \pm 0.14 & 3.38 & 3.19 & -1.38 & 0.171 \\
\hline Joint decision making to transfer extension messages to farmers & 3.23 & \pm 0.14 & 3.24 & 3.23 & -0.06 & 0.950 \\
\hline Joint planning of research programs & 3.24 & \pm 0.14 & 3.25 & 3.23 & -0.16 & 0.871 \\
\hline Joint M\&E of R\&E activities & 3.31 & \pm 0.15 & 3.46 & 3.13 & -2.26 & 0.026 \\
\hline Incentives to promote cooperation between R\&E activities* & 3.63 & \pm 0.11 & 3.65 & 3.60 & -0.37 & 0.711 \\
\hline Emphasizing linkages in the job description for Rs and EAs & 3.24 & \pm 0.15 & 3.27 & 3.21 & -0.39 & 0.698 \\
\hline Participation of researchers in training activities of extension agents & 3.33 & \pm 0.14 & 3.42 & 3.21 & -1.43 & 0.154 \\
\hline Participation in carrying out extension activities & 3.36 & \pm 0.12 & 3.49 & 3.21 & -2.39 & 0.018 \\
\hline Joint participation in preparation of TV and Radio programs & 3.23 & \pm 0.15 & 3.19 & 3.28 & 0.62 & 0.535 \\
\hline Joint participation of printed educational materials & 3.33 & \pm 0.14 & 3.40 & 3.25 & -1.08 & 0.283 \\
\hline Overall & 33.26 & \pm 0.89 & 33.67 & 32.71 & -1.10 & 0.274 \\
\hline
\end{tabular}

R; stands for research, Rs; stands for researchers, E; stands for extension, EAs; stands for extension agents 
Table 3. Differences between researchers and extension agents mean score of rating of the organizational scale

\begin{tabular}{|c|c|c|c|c|c|c|}
\hline \multirow[b]{2}{*}{ Items } & \multirow[b]{2}{*}{$\begin{array}{l}\text { Overall } \\
\text { mean }\end{array}$} & \multirow[b]{2}{*}{$\% 95 \mathrm{CI}$} & \multicolumn{2}{|c|}{ Item mean } & \multirow[b]{2}{*}{$\mathrm{t}$-value } & \multirow[b]{2}{*}{$\mathrm{p}$-value } \\
\hline & & & $\mathrm{R}$ & EA & & \\
\hline Institutional R\&E framework & 3.12 & \pm 0.17 & 3.18 & 3.06 & -0.710 & 0.478 \\
\hline Formal merger of R\&E & 2.84 & \pm 0.19 & 2.75 & 2.96 & 1.120 & 0.264 \\
\hline Assigning technology transfer to the NCARE & 2.64 & \pm 0.19 & 2.85 & 2.37 & -2.580 & 0.011 \\
\hline Integrated cycle of technology transfer in research programs for selected crops & 3.02 & \pm 0.15 & 3.16 & 2.83 & -2.120 & 0.036 \\
\hline Creating units to manage R\&E relationships and exchange information & 3.04 & \pm 0.16 & 3.18 & 2.87 & -1.900 & 0.061 \\
\hline Specific procedures for linkages & 2.82 & \pm 0.15 & 2.81 & 2.83 & 0.130 & 0.894 \\
\hline Creation of national council or committee to undertake linkages & 2.93 & \pm 0.14 & 2.84 & 3.04 & 1.180 & 0.240 \\
\hline Formulating high committee in the MOA to coordinate R\&E activities & 2.96 & \pm 0.16 & 2.78 & 3.19 & 2.520 & 0.013 \\
\hline Formulating national coordinating committee of R\&E activities & 2.98 & \pm 0.16 & 2.82 & 3.17 & 2.110 & 0.037 \\
\hline Formulating regional coordinating committees to $R \& E$ activities. & 3.03 & \pm 0.15 & 3.01 & 3.04 & 1.150 & 0.881 \\
\hline Overall & 29.34 & \pm 1.09 & 29.50 & 29.30 & -0.096 & 0.924 \\
\hline
\end{tabular}

R; stands for research, Rs; stands for researchers, E; stands for extension, EAs; stands for extension agents

Table 4. Differences between researchers and extension agents mean score of the universities scale

\begin{tabular}{|c|c|c|c|c|c|c|}
\hline \multirow[b]{2}{*}{ Items } & \multirow[b]{2}{*}{$\begin{array}{l}\text { Overall } \\
\text { Mean }\end{array}$} & \multirow[b]{2}{*}{$\% 95 \mathrm{CI}$} & \multicolumn{2}{|c|}{ Item Mean* } & \multirow[b]{2}{*}{$Z^{* *}$} & \multirow[b]{2}{*}{$\mathrm{P}$} \\
\hline & & & $\mathrm{R}$ & EA & & \\
\hline Faculties Of Agriculture (FOAs) have to be integrated in a unified ARES. & 3.01 & \pm 0.20 & 3.12 & 2.87 & -1.24 & 0.214 \\
\hline FOAs should participate in setting up research priorities & 2.69 & \pm 0.19 & 2.63 & 2.75 & -0.58 & 0.563 \\
\hline The core value of university research is the applicability of the results & 2.89 & \pm 0.20 & 3.07 & 2.66 & -2.02 & 0.043 \\
\hline FOAs should be actively involved in the R\&E workshops & 2.99 & \pm 0.20 & 3.06 & 2.91 & -0.86 & 0.388 \\
\hline FOAs should participate in training of researchers and extension agents & 2.98 & \pm 0.19 & 3.00 & 2.94 & -0.01 & 0.993 \\
\hline Collaborative applied research and joint publications of research works & 3.07 & \pm 0.19 & 3.10 & 3.02 & -0.37 & 0.711 \\
\hline FOAs can contribute in research to develop farm management activities & 2.85 & \pm 0.19 & 2.84 & 2.87 & 0.25 & 0.803 \\
\hline FOAs can contribute in promoting market research and export products & 2.82 & \pm 0.20 & 2.81 & 2.83 & 0.13 & 0.894 \\
\hline Overall & 23.29 & \pm 1.29 & 21.00 & 24.58 & -0.59 & 0.526 \\
\hline
\end{tabular}

*; Rs stands for researchers, EAs stands for extension agents **; Mann Whitney for (M-W) test

Table 5. Associations between attitudes to linkages and selected variables (121 cases)

\begin{tabular}{|c|c|c|c|c|c|c|c|}
\hline \multirow[b]{2}{*}{ Independent variables } & \multirow[b]{2}{*}{ Test } & \multicolumn{2}{|l|}{ Overall } & \multicolumn{2}{|c|}{ Researchers } & \multicolumn{2}{|c|}{ Ext. Agents } \\
\hline & & Test & $\mathrm{P}$ & Test & $\mathrm{P}$ & Test & $\mathrm{P}$ \\
\hline \multicolumn{8}{|l|}{ Management Linkages } \\
\hline Sex (Male, female) & t-test & $t=0.66$ & 0.513 & $\mathrm{t}=0.82$ & 0.420 & $t=0.33$ & 0.74 \\
\hline Age group $(<30,30-39,40-49, \geq 50 \mathrm{Yrs})$ & KW-test & $\chi^{2}=3.19$ & 0.236 & $\chi^{2}=1.21$ & 0.750 & $\chi^{2}=5.57$ & 0.13 \\
\hline Education ( $\leq$ BSc, MSc, Ph.D) & KW-test & $\chi^{2}=0.35$ & 0.950 & $\chi^{2}=1.11$ & 0.570 & $\chi^{2}=2.41$ & 0.30 \\
\hline Years of service $(<6,6-10,11-16, \geq 15 \mathrm{Yrs})$ & ANOVA & $\mathrm{F}=3.55$ & 0.017 & $\mathrm{~F}=2.9$ & 0.040 & $\mathrm{~F}=0.84$ & 0.45 \\
\hline No. of training courses & rho & -0.249 & 0.006 & -0.382 & 0.001 & -0.079 & 0.57 \\
\hline \multicolumn{8}{|l|}{ Organizational linkages } \\
\hline Sex & t-test & $\mathrm{t}=-0.88$ & 0.379 & $t=-0.64$ & 0.528 & $t=-0.62$ & 0.54 \\
\hline Age group & ANOVA & $\mathrm{F}=0.39$ & 0.762 & $\mathrm{~F}=0.45$ & 0.718 & $\mathrm{~F}=0.08$ & 0.97 \\
\hline Education & ANOVA & $F=0.26$ & 0.956 & $F=0.88$ & 0.421 & $F=0.47$ & 0.63 \\
\hline Years of service & ANOVA & $\mathrm{F}=1.21$ & 0.308 & $\mathrm{~F}=2.07$ & 0.113 & $F=0.46$ & 0.71 \\
\hline No. of training courses & rho & -0.19 & 0.040 & -0.26 & 0.032 & -0.09 & 0.52 \\
\hline \multicolumn{8}{|l|}{ Universities linkages } \\
\hline Sex & MW-test & $Z=-0.84$ & 0.40 & $Z=-0.21$ & 0.833 & $Z=-1.05$ & 0.30 \\
\hline Age group & KW-test & $\chi^{2}=3.19$ & 0.36 & $\chi^{2}=1.21$ & 0.750 & $\chi^{2}=5.57$ & 0.13 \\
\hline Education & KW-test & $\chi^{2}=0.4$ & 0.95 & $\chi^{2}=1.1$ & 0.574 & $\chi^{2}=2.4$ & 0.30 \\
\hline Years of service & KW-test & $\chi^{2}=7.2$ & 0.07 & $\chi^{2}=10.3$ & 0.016 & $\chi^{2}=1.8$ & 0.61 \\
\hline No. of training courses & rho & -0.249 & 0.006 & -0.382 & 0.001 & -0.079 & 0.57 \\
\hline
\end{tabular}

ANOVA stands for Analysis of Variance; KW stands for Kruskal Wallis test 


\section{DISCUSSION}

\subsection{Sample Characteristics}

Researchers and extension agents' characteristics are important factors in shaping their perceptions and attitudes towards linkages between research and extension. Table 1 indicates that researchers appear to be relatively younger than extension agents as $23 \%$ were found to be less than 30 years $(\bar{x}=35.8$ Yrs $)$, against $17 \%$ for extension agents $(\bar{x}=36.5$ Yrs $)$. Higher percentage of extension agents $(79 \%)$ was found to be married than researchers $(69 \%)$ and higher percentage of extension agents $(75 \%)$ were found to have five years of experience or more than researchers $(68 \%)$. The percentage of male extensionists $(81 \%)$ was higher than researchers $(73 \%)$ as extension work is largely a long and hard field work, not preferred by female agents and farmers are less receptive to technical advice coming from female agents due to cultural traditions. Percentages of respondents with an MSc or $\mathrm{PhD}$ degree were significantly higher for researchers (44\%) than extensionists $(9 \%)$. Thus, researchers are relatively younger, more open to women work, more educated, but they have less experience.

\subsection{Attitudes towards Research and Extension Linkages}

The R\&E activities in Jordan were initiated in the early $1950 \mathrm{~s}$, but they were merged and separated several times and operated under different management. The last episode was in 2007, when R\&E activities were finally reunited under the umbrella of the National Center for Agricultural Research and Extension (NCARE, 2009). Agricultural higher education started in 1972 with the inception of the Faculty of Agriculture at the University of Jordan. Later, four other faculties of agriculture were established. For most faculties, physical and financial resources are essentially allocated to training activities and research facilities, equipment and funds are considered insufficient. The faculties suffer from low research budgets, which prevented a fair mobilization of their scientific potential (Snobar and Duwayri, 1996). Research and extension linkage are achieved through different means. These include; memberships in councils, participation of the faculty members in the NCARE research committees, joint research activities and publications by scientists from different institutions, joint field days and seminars. Extension agents are not actively involved in the research process. The ARES is a conventional system, as the transfer of technology follows the top-down approach, which does not involve farmers when identifying constraints and adapting research to local conditions (Casas, 1999). The farmer is not seen and recognized to be a primary client of research and so should be involved in the various stages of research and thus influence research priorities and the design of technological solutions based on constraints identified (Asopa and Beye, 1997). The result is that linkage activities are not carried out in an effective way through a well-defined system. The weakness of linkages in the ARES means a poor use of the limited natural and financial. General attitudes towards linkages appear to be higher for researchers as compared to extension agents. One third of the researchers $(34 \%)$ were found to have low attitudes against $46 \%$ of the extension agents and $19 \%$ of the researchers were found to have high attitudes against $6 \%$ of the extension agents. The association, however, was statistically of low significance $\left(\chi^{2}=5.088\right.$, $\mathrm{P}$-value $<0.079)$. This supports the earlier finding that the overall attitudes were found to be generally high.

\subsection{Attitudes towards Research and Extension Management Linkages}

The 10-item management scale was used to measure the attitude of researchers and extension agents towards research-extension management oriented linkages. The items of the scale and their statistics are presented in Table 2. Mean scores indicate the average level of agreement with an item. The item mean scores ranged between 3.24 to 3.63 and the overall per item mean score was 3.33 (83\% of the maximum scale score which is 40 ). The overall mean score of the scale was 33.26 , which indicates the overall level of agreement with all items in the management scale. The management scale scores ranged between 21 and 40 points. Only 16.2\% had ratings beyond one standard deviation above the mean. Most of the respondents (81-93\%) scored 3-4 points on individual items of the scale and about half of them scored 4 points, which resulted in negatively skewed distribution of the management scale scores. These results suggest that attitudes of the respondents were high indeed towards a range of managerial interventions. For example, researchers and extension agents may agree to emphasize linkages in the job description for researchers and extension agents and to collaborate on conducting surveys to identify and assess farmers' problems. They may agree on joint decision making on technical recommendations, monitoring and reviews of $\mathrm{R} \& \mathrm{E}$ activities and in functions such as 
preparation of TV and radio programs and in leaflets and folders writing. The need to make performance assessments and impact evaluations are inherent components of any extension program so as to increase the effectiveness of extension service reforms. Other types of related managerial interventions include joint planning of annual R\&E programs (e.g., on-farm trials), assigning SMSs to a regional experiment station to work directly with one or more research teams, participation of researchers in workshops and training activities of extension agents and in carrying out extension activities (e.g., field days, demonstrations). Other types include providing individual professional and financial incentives for collaboration and cooperation in areas such as joint use of facilities and services, e.g., soil testing, exchange of personnel and information using jointly developed protocols (Asopa and Beye, 1997). Linkage between research and farmers in an effective R\&E system cannot be made without well qualified and highly trained extension SMSs. In short, through collaborative program activities, R\&E personnel can develop a positive professional relationship that is essential in facilitating the flow of technology and feedback information within an ARES (Swanson, 1997). Although the overall and item mean scores of the management scale appear to be higher for researchers as compared to extension agents as Table $\mathbf{2}$ shows, differences were statistically insignificant, apart from joint monitoring and reviews of $R \& E$ activities and participation in carrying out extension activities such as demonstrations, on-farm trials and field days, as researchers appear to have more positive attitudes $(\mathrm{p}<0.05)$.

\subsection{Attitudes towards Organizational Research and Extension Linkages}

The 10-item organisational scale was used to measure the attitude of researchers and extension agents towards research-extension organisational oriented linkages. The items of the scales and their statistics are presented in Table 3. The item mean scores ranged between 2.65 to 3.13 and the overall per item mean score was 2.93 . The overall mean scores of the scale were 29.34 ( $73 \%$ of the maximum scale score), which indicate the overall level of agreement with all items in the scale. The scale scores ranged between 13 and 40 points. Only $15.1 \%$ had ratings beyond one standard deviation above the mean. The majority of the respondents (61-77\%) scored 3-4 points on individual items of the organisational scale and about two fifths of them scored 4 points, which resulted in negatively skewed distribution of the management scale. These results suggest that attitudes of the respondents were high towards a range of structural modifications, but much less than their attitudes towards managerial interventions.

Exploring and institutionalizing linkages with other organizations presents a viable strategy for extension organizations to obtain information and educational resources for use when reaching out to farmers for improving the efficiency of the scarce financial resources available (Munyua et al., 2002). The structural modifications of the research and/or extension organization involve a range of measures from formal merger of R\&E in one institution to formulating national council or regional coordinating committees of $\mathrm{R} \& \mathrm{E}$ activities, or formulating high technical committee in the ministry to coordinate R\&E activities. Merrill-Sands (1992) noticed that in creating a permanent committee, it should be comprised of senior members to be able to implement decisions and recommendations, members should meet regularly and their work should be supported by senior management (Swanson, 1997). Modifications could involve the creation of departments or units to manage $R \& E$ relationships and exchange information. Other types of related structural modifications to undertake ARES linkages include assigning technology transfer to the research center, integrating all cycles of technology transfer in research programs for selected crops, defining specific procedures for linkages through signing inter-agency agreements and memorandums of understanding. Swanson (1997) mentioned that in some cases it might be appropriate to create a coordination position, such as an R\&E liaison officer or to explicitly assign coordination functions to a specific position or unit (e.g., SMSs). Researchers and extension agents were largely indifferent in their overall mean score of the organizational scale. However, their attitudes were not consistent towards the possible structural modifications. The item mean scores were significantly higher for the researchers with respect to integrating all cycles of technology transfer in research programs for selected crops, or in general $(p<0.05)$ and less significant for creating departments or units to manage $R \& E$ relationships and exchange of information. These results suggest that researchers were more positive to measures that would give more control on the technology transfer activities, while it is perceived by the extension agents as a policy of marginalization of extension. In contrast, the item mean scores were significantly higher for the extension agents with respect to formulating high 
technical committee in the MOA to coordinate R\&E activities, or formulating national coordinating committee of $R \& E$ activities $(p<0.05)$. These results suggest that the extension agents were more positive to measures that are oriented to coordination and would give less control to the national centre for research over the technology transfer activities to avoid possible marginalization.

\subsection{Attitudes towards Universities Research Linkages}

The mandate of the Faculties of Agriculture (FAs) does not include any form of institutional relationship with extension services and the field contacts are limited between academic members and farmers or extension agents. Staff members with $\mathrm{PhD}$ degrees are appointed on the bases of needs for teaching. Therefore, AR activities carried out at the faculties are often not of problem-solving nature, but they are carried out for academic advancement purposes (Taimeh and Sunna, 1999). Thus, results often remain in publications and not readily available to farmers and therefore not applied (Snobar and Duwayri, 1996). The result is that AR impact is largely restricted to improvement of cereal, food legume and forage production (Casas, 1999). The 8-item universities scale is presented in Table 4. It was used to measure the attitude of researchers and extension agents towards R\&E linkages with universities. The overall item mean score was 2.91 and the overall scale mean score was $23.29(72.8 \%$ of the maximum score which is 32), which indicates the overall level of agreement with all items in the universities scale. The core value of university research is the applicability of the results. The universities scale involve a range of measures such as; integrating FAs in a unified ARES, participation of the FAs in setting up research priorities, R\&E workshops, training of researchers and extension agents and collaborative applied research. Other types of related linkages with universities include contribution in research to develop farm management activities, promoting market research and export products and publication of research works and educational materials.

Although the item mean scores of the universities scale appear to be higher for researchers for most of the research oriented items as compared to extension agents, differences were statistically insignificant (MannWhitney test), apart from their attitudes to the core value of university research with respect to the applicability of the results, in which the item mean score was significantly higher for the researchers $(p<0.05)$ as shown in Table 4. These results suggest that respondents are alike in their positive attitudes to measures that would promote integrating faculties of agriculture in a unified ARES and in more collaborative, focused and applied research programs that have to be designed by the research providers to effectively address high priority local need.

\subsection{Associations between Attitudes to Linkages and Selected Variables}

Based on approximations of the scales to the normal distribution, Table 5 presents the results of parametric tests ( $\mathrm{t}),($ ANOVA) and non-parametric tests (K-W) and (rho) tests to investigate the differences in the mean ratings of attitude by attributes or correlations between the ratings and the ordinal independent variables. These attributes include sex, age groups, education, years of service and number of training courses.

Significant differences in the mean ratings were observed by the number of training courses for the three scales for the overall sample and for researchers $(p<0.05)$. Similarly, significant differences were observed for years of service for the management and universities scales for the overall sample and researchers, but not for extension agents $(p<0.05)$. The results suggest that the more trained and experienced and married researchers were more likely to value highly stronger linkages. Relationships with other attributes for the three scales were not statistically significant, which suggest that respondents were alike in their attitudes irrespective of these attributes.

\section{CONCLUSION}

Overall attitudes towards research extension linkages were found to be generally high, as the mean overall scores for the three scales were $73-83 \%$ of the maximum scores. But, researchers' attitudes appear to be higher as compared to extension agents. The association, however, was statistically of low significance $(p<0.10)$. Researchers' attitudes were significantly higher for some of the managerial interventions, such as joint monitoring and reviews of R\&E activities and participation in carrying out extension activities $(p<0.05)$. Their attitudes were also significantly higher for many of the organizational linkages and towards the core value of university research with respect to the applicability of the results, in which the item mean score was significantly higher for the researchers $(p<0.05)$. 
The extension agents were more in favor to linkage measures that are oriented to management interventions over the technology transfer activities to avoid possible marginalization. Respondents were alike in their positive attitudes to measures that would promote integrating faculties of agriculture in a unified ARES and in more collaborative, focused and applied research programs that have to be designed by the research providers to effectively address high priority local need. Attitudes of extension agents and researchers were quite similar towards strengthening R\&E linkages, as no statistically significant associations were observed between attitudes and most of the selected demographic and professional characteristics. Researchers appear to be relatively younger, more open to women work, more educated, but they have less experience. The more experienced researchers, with higher training chances were more likely to value stronger linkages.

Research and extension linkage are achieved through different means, but, they are not carried out in a welldefined system in Jordan. Linkage becomes effective with a common purpose and perceived advantages for institutional collaboration. With the positive attitudes towards more formal linkages, achieving active complimentarity contributes to addressing national issues under the constraints of limited resources. An effective linkages system would be achieved by implementing elements of varied types of mechanisms that are environment sensitive and situation specific. Progressive adoption of measures aimed towards integration of the human, physical and financial resources of the actors of the ARES helps in capacity building and helps the extension agents to rise above their fears of possible marginalization and to be more positive to institutional linkages.

Institutional reforms to bridge information gaps are vital in view of the weak R\&E linkages. Setting up a broad-based committee is recommended; to coordinate activities, to strengthen linkages and to determine how AR efforts can best be allocated to meet the most urgent research and technology transfer needs. Adopting a clear mandate and division of labour integrates activities that link stages of technology transfer. The best extension cannot compensate for irrelevant or ineffective research. Applied and adaptive research programs, to be relevant, have to focus on high-priority national issues and production challenges that are location-specific and to securing applications to the end-user farmers, to ensure that the research output does get into use. Faculties of Agriculture have to be integrated in a unified ARES to ensure their focus on key strategic and applied researchable issues and that the applicability of the results have to be in the core of the research programs of the academic departments.

\section{ACKNOWLEDGMENT}

The research has been supported by the Deanship of Scientific Research of the University of Jordan.

\section{REFERENCES}

Agbamu, J.U., 2000. Agricultural research-extension linkage systems: An international perspective. Agricultural Research and Extension Network.

Asopa, V.N. and G. Beye, 1997. Management of agricultural research: A training manual. Food and Agriculture Organization of the United Nations.

Belaid, A., M. Solh and A. Mazid, 2003. Setting agricultural research priorities for the central and West Asia and North Africa Region. ICARDA, Aleppo, Syria.

Blum, A., 1994. A Confederate agricultural knowledge system: The special case of Switzerland. Eur. J. Agric. Educ. Exten., 1: 103-117.

Casas, J., 1999. Economy and agriculture of the WANA region. WANA NARS Study.

Chizari, M. and R. Movahedi, 2005. Effectiveness of joint extension-research plans based on perceptions of extension agents and researchers in Lorestan and Kermanshah provinces, Iran. Proceedings of the 21th Annual Conference of the International Agricultural and Extension Education, May 25-31, San Antonio, TX, USA.

Crowder, L. and J. Anderson, 1996. Integrating agricultural research, education and extension in developing countries. sustainable Develpment Department (SD), Food Agriculture Oragnization of the United Nations (FAO).

Gould, R. and G. Ham, 2002. The integration of research and extension: A preliminary study. J. Extens.

Henneman, R.A., 2006. Cronbach's alpha reliability analysis with SAS. University of California.

Marsh, S.P. and D.J. Pannell, 2000. Agricultural extension policy in Australia: The good, the bad and the misguided. Aus. J. Agric. Resource Econ., 44: 605-627.

Merrill-Sands, D., 1992. Managing links with technology users: A training module. The Hague: International Service for National Agricultural Research. 
MOA, 1997. The agricultural policy. Ministry of Agriculture, Jordan.

MOA, 1998. National strategy for agric. Extension. Ministry of Agriculture, Jordan.

MOA, 2001. Agricultural development program. Ministry of Agriculture, Jordan.

Munyua, C.N., P.F. Adams and J.S. Thomson, 2002. Designing effective linkages for sustainable agricultural extension information systems among developing countries in Sub-Saharan Africa. Proceedings of the 18th Conference of the Association of International Agricultural and Extension Education, (AEE' 02), Durban, South Africa, pp: 301-307.

Murray, M., 1999. A contrast of the australian and california extension and technology transfer processes. J. Exten.

NCARE, 2009. National agricultural document. The National Center for Agricultural Research and Extension, Jordan.

NCARTT, 1996. National agricultural research strategy. The National Center for Agricultural Research and Technology Transfer, Jordan.

Peterson, W., V. Galleno, T. Eponou, A. Wuyts-Fivawo and W. Wilks, 2001. Methods for planning effective linkages. International Service for National Agricultural Research.

Qtaishat, T. and A. AL-Sharafat, 2012. Attitudes of vegetable farmers towards public agricultural extension services. Am. J. Agric. Biol. Sci., 7: 370377. DOI: 10.3844/ajabssp.2012.370.377

Reynaldo, J. and A. Santos, 1999. Cronbach's Alpha: A tool for assessing the reliability of scales. J. Extens.
Rimawi, A., 2010. The regional brief of the association of agricultural research institutions in the Near East and North Africa. Proceedings of the International Workshop on the Fast Growing Economies' Role in Global Agricultural Research for Development, (ARD’ 10), Beijing, China.

Rivera, W.M., G. Alex, J. Hanson and R. Birner, 2006. Enabling agriculture: The evolution and promise of agricultural knowledge frameworks. Proceedings of the 22th Annual Conference of the Association of International Agricultural and Extension Education, (AEE' 06), Clearwater Beach, Florida, pp: 580-591.

Sadighi, H., 2005. Research, education and extension linkages: An analysis of institutions in developing countries. Proceedings of the 21th Annual Conference of the Association for International Agricultural and Extension Education, (AEE' 05), San Antonio, TX, pp: 117-125.

Snobar, H. and M. Duwayri, 1996. The Role of Universities in the NARSs of Egypt, Jordan, Morocco, Sudan and Tunisia. Case Study 2, FAO, Jordan, Rome.

Swanson, B.E, 1997. Strengthening ResearchExtension-Farmer Linkages. In: Improving Agricultural Extension: A Reference Manual, Swanson, B.E. (Ed.), Food and Agriculture Organization of the United Nations, Rome, ISBN10: 9251040079, pp: 171-178.

Taimeh, A. and S. Sunna, 1999. The National Agricultural Research System of Jordan. WANA NARS Study. 